\title{
Determinantes da escolarização de crianças e adolescentes em situação de rua no estado de Minas Gerais
}

Frederico Poley Martins Ferreira *

Reginaldo Pinto Nogueira Junior**

Bruno Lazzarotti Diniz Costa ${ }^{*+*}$

\section{Resumo}

0 artigo investiga os determinantes do acesso à educação de crianças e adolescentes em situação de rua no estado de Minas Gerais. Os dados utilizados se baseiam em uma ampla pesquisa realizada nos 21 maiores municípios do estado, que culminou com a coleta de diversas informações de um total de 3.028 crianças e adolescentes que moram ou exercem alguma atividade remunerada nas ruas. Com base nesses dados, estimou-se um modelo Logit, que permitiu identificar a correlação entre diversas variáveis e o acesso à educação. Os resultados encontrados vão na direção dos principais desenvolvimentos da literatura, demonstrando a influência negativa, entre outros fatores, do número de dias trabalhados, moradia na rua, da idade, da gravidez na adolescência, e da localização em município da região metropolitana. Por outro lado, políticas públicas de transferência de renda parecem ampliar as possibilidades de estudo para as crianças e adolescentes que trabalham ou vivem nas ruas.

Palavras-chave: Trabalho infantil. Acesso à educação. Desigualdade educacional.

\section{Determinants of primary and secondary education among street children and teenagers in Minas Gerais State Abstract}

We investigate the determinants of primary and secondary education among street children and teenagers in the Minas Gerais state. Our dataset consists of

* Doutor em Demografia, Universidade Federal de Minas Gerais (UFMG); Centro de Estatística e Informações, Fundação João Pinheiro. E-mail: frederico.poley@fjp.mg.gov.br

** Doutor em Economia, University of Kent at Canterbury, Reino Unido; IBMEC-MG. E-mail: rpnjunior@yahoo.com.br

*** Doutor em Sociologia e Política, UFMG; Escola de Governo, Fundação João Pinheiro. E-mail: bruno.diniz@fjp.mg.gov.br 
3.028 questionnaires applied to children and teenagers found in the streets of the 21 largest cities in the state. We have estimated a Logit model, which enabled us to identify the correlation between several variables and the overall access to education. The results found go in line with recent developments in the literature, indicating the negative influence of variables such as number of working days, age, teenage pregnancy, residence in metropolitan area, among others. Moreover, conditional transfers and other government programs seem to have a positive effect on magnifying the access to education among children and teenagers living and working on the streets.

Keywords: Child Labor. Education inequality. Access to education.

\section{Determinantes de la escolarización de niños $y$ adolescentes de la calle en el estado de Minas Gerais \\ Resumen}

El artículo analiza los determinantes del acceso a la educación de niños y adolescentes de la calle en el estado de Minas Gerais. Los datos provienen de una investigación amplia llevada a cabo en 21 ciudades del estado, incluyendo las más grandes. La investigación permitió recolectar información acerca de 3028 niños y adolescentes que viven o trabajan en las calles. A partir de estos datos, se estimó un modelo Logit, lo que permitió identificar la correlación entre diversas variables y el acceso a la educación. Los resultados hallados tienen relación con los principales desarrollos de la literatura, lo que demuestra, entre otros factores, la influencia negativa del número de días trabajados, de la estadía en la calle, la edad, el embarazo en la adolescencia, y la ubicación en municipio de la región metropolitana. Por otro lado, políticas públicas, como programas de transferencia de renta, parecen aumentar el acceso a la escuela por parte de los niños entrevistados.

Palabras clave: Trabajo infantil. Acceso a la educación. Desigualdad educativa.

\section{Introdução}

É bastante conhecido o caráter altamente insatisfatório das condições educacionais brasileiras. Nesse sentido, a distribuição da educação no Brasil apresenta diversas características, como nível educacional médio muito baixo; distribuição muito desigual da escolaridade da população; ausência de igualdade de oportunidades educacionais, expressa pela alta correlação entre o nível educacional das crianças e o de seus pais e avós; e graves disparidades regionais nos níveis de educação (VALLE; HASENBALG, 2000). 
Este trabalho analisa, porém, os determinantes do acesso à educação de crianças e adolescentes que compartilham uma condição específica e aguda de vulnerabilidade: eles têm as ruas como referências centrais de vida ou de trabalho. Este estudo presta-se, portanto, a uma avaliação ou qualificação da literatura sobre a equidade de oportunidades educacionais: as evidências para este grupo permitem discutirem-se se os fatores que, de maneira geral, explicam a desigualdade educacional da população permitiriam também, mesmo em condições particularmente agudas de vulnerabilidade, explicar o acesso diferenciado à educação.

Os resultados apresentados por este artigo se baseiam em uma pesquisa realizada em 21 municípios do estado de Minas Gerais, ao final de 2007, e que teve como objeto de estudo todas as crianças e adolescentes com idade até 18 anos incompletos que estivessem morando ou exercendo algum tipo de atividade remunerada nas ruas. No total, foram aplicados 3.028 questionários, o que nos permitiu delinear um panorama da qualidade de vida, da situação familiar, das expectativas sobre o futuro, e do acesso à educação de crianças e adolescentes em situação de rua no estado. Com base nas respostas, estimou-se um modelo econométrico (Logit) que nos permitiu identificar os principais determinantes da escolarização nesse público particularmente vulnerável.

Os resultados encontrados montam um cenário relativamente claro sobre os determinantes da escolarização de crianças e adolescentes em situação de rua no estado de Minas Gerais. Em especial, percebeu-se a influência negativa do número de dias trabalhados, da situação de rua, número de irmãos, da idade, da gravidez na adolescência, e da localização em município da região metropolitana. Por outro lado, políticas públicas de transferência de renda parecem ampliar as possibilidades de estudo para as crianças e adolescentes mais pobres. Tais politicas devem ser não apenas incentivadas, mas complementadas por políticas que foquem na manutenção dos adolescentes nas escolas, que retirem crianças e adolescentes das ruas, e que aprimorem a qualidade de vida nas regiões metropolitanas.

0 artigo está divido em três seções, além dessa Introdução. Na segunda Seção é apresentada uma análise teórica a respeito de equidade e desigualdade educacional, e são apresentadas algumas hipóteses a respeito dos determinantes do acesso à educação por parte de crianças e adolescentes em situação de rua. Na terceira Seção é apresentada uma análise empírica do tema, primeiramente com uma análise da base de dados e da metodologia de trabalho, e em seguida com a apresentação dos resultados encontrados na estimação. Finalmente, na quarta Seção são apresentados alguns comentários finais. 


\section{Análise teórica}

Uma avaliação da desigualdade educacional exige uma definição mínima do conceito de equidade, dado o grau de ambiguidade do termo e os sentidos diversos com que tem sido utilizado. Esta discussão permitirá, em seguida, operacionalizar um conjunto de hipóteses analíticas que orientarão a exploração empírica na seção seguinte.

0 conceito de equidade tem sido objeto de intensa reflexão, debate e pesquisa em vários campos do conhecimento, desde a filosofia até áreas mais aplicadas, como a avaliação de políticas públicas. Nem de longe é objetivo deste trabalho cobrir os termos e posições desse debate. A menção extremamente simplificada a alguns deles tem, aqui, unicamente o objetivo de estruturar a discussão posterior.

Apesar de ser possivel orientar o debate sobre a equidade em diferentes referenciais, como diversas concepções de justiça (principalmente justiça distributiva) ou como garantia de certos direitos básicos, no tocante às políticas sociais, a discussão sempre tendeu a se orientar em torno de alguma noção de igualdade (VAN PARIJS, 1993; SEN, 1997; CALERO; BONAL, 1999; MOKATE, 2001). Entretanto, a partir dai vários tipos de questões podem ser colocadas. Uma delas refere-se à pergunta: Igualdade entre quem? A partir da resposta a essa questão, podem-se distinguir as noções simplificadas de equidade vertical e de equidade horizontal (MOKATE, 2001).

A concepção vertical de equidade diz respeito à necessidade de tratamento igual entre todos os membros de uma sociedade, apontando para uma sobreposição do conceito de equidade ao de igualdade absoluta de tratamento. Ao contrário, a noção de igualdade horizontal refere-se à admissibilidade de tratamento diferenciado entre grupos diferentes entre si, ou seja, ao tratamento igual para iguais. Desse ponto de vista, poderia haver tratamento diferenciado entre grupos não necessariamente injusto. Para quem defende essa noção de equidade, a dificuldade resulta, então, em responder quais diferenças de tratamento seriam justas. Principalmente a partir do trabalho de Rawls, a resposta mais comum a esse tipo de questão é a de que serão justas aquelas diferenças (ou desigualdades) de tratamento que corrijam desigualdades anteriores ou que aproximem os individuos e grupos de uma condição inicial de igualdade de oportunidades de competição quanto a certos recursos básicos, como acesso à educação, à saúde, entre outras condições (VAN PARIJS, 1993). Desse ponto de vista, seria justificado, por exemplo, o desenvolvimento de programas governamentais educacionais focalizados em populações mais vulneráveis, já que isso seria consistente com a função de correção de desigualdades existentes entre os grupos quanto à renda, à propriedade, à educação dos pais, ao acesso ao consumo cultural, dentre muitas outras. 
Em contextos de grandes desigualdades, como o da sociedade brasileira, essa distinção adquire particular relevância, pois implica dizer que um tratamento ou uma oferta de serviços educacionais podem ser igualitários e, ao mesmo tempo, iníquos. Por exemplo, no que tange à educação, sabe-se que os diferentes grupos sociais apresentam capacidade desigual de utilizar os recursos educacionais disponibilizados, em virtude de fatores extraeducacionais, como as condições econômicas, culturais, educacionais e sociais das famílias. Portanto, uma política de oferta educacional absolutamente igualitária tenderia a reproduzir a desigualdade de oportunidades prévia, sendo, portanto, pouco equitativa'. Considerando-se as graves desigualdades de oportunidades educacionais no Brasil, a análise dos impactos e das condições de equidade das políticas educacionais será feita levando em conta esse critério "horizontal" e simplificadamente "rawlsiano" de avaliação.

0 segundo tipo de questão que a avaliação de equidade na política educacional levanta é aquela relativa à pergunta: Igualdade de quê? No tocante à educação, o primeiro tipo de especificação com relação a esse aspecto refere-se à distinção entre equidade externa e equidade interna. A equidade externa, da qual não se tratará aqui, refere-se às desigualdades entre os diferentes grupos sociais (gênero, cor, estratos de renda, grupos urbanos ou rurais) quanto aos impactos de médio e longo prazos da política educacional, sendo, portanto, consequências futuras esperadas dos serviços prestados sobre a sociedade, mas que ocorrem em âmbitos externos aos dos serviços educacionais propriamente ditos. No caso da educação, tem a ver com os níveis de escolaridade que os diferentes grupos conseguem alcançar, sua produtividade, seu desempenho como cidadãos ou como país, por exemplo.

Já a equidade interna, da qual se tratará aqui, principalmente no caso de Minas Gerais, refere-se ao âmbito interno dos serviços educacionais e ao acesso e à capacidade de atendimento aos diversos grupos sociais por parte do sistema educacional. Tem a ver, por exemplo, com os niveis diferenciados de acesso, abandono, de reprovação e de aprendizagem que o sistema educacional é capaz de garantir aos diferentes grupos sociais, o que pode contribuir para reduzir, reproduzir ou ampliar as desigualdades sociais existentes.

No plano da equidade interna, uma resposta à pergunta Igualdade de quê? - que orientou durante bastante tempo o debate em torno da igualdade de oportunidades educacionais - era bastante simples, apesar de demorar bastante a se realizar (e, no caso brasileiro, estar ainda distante da universalização): a equidade na política educacional significaria igualdade na cobertura e qualidade da oferta de serviços educacionais. Ou seja, garantir uma oferta universal e homogênea de serviços educacionais a todos os grupos sociais independentemente de classe social, renda, cor, sexo, etc. (COLEMAN, 1966). Entre-

1 Para o caso brasileiro, no entanto, uma política de oferta de educação totalmente igualitária já significaria um avanço em termos de equidade, uma vez que historicamente o que ocorre é uma estrutura de oferta regressiva, na qual as escolas que atendem as populações mais vulneráveis são aquelas cujos corpos técnicos e docentes são menos qualificados, e nas quais as condições físicas são muito piores. 
tanto, à medida que os estudos sobre a desigualdade de oportunidades educacionais avançavam, foi-se tornando cada vez mais claro que um foco exclusivo sobre a oferta educacional negligenciaria que os diferentes grupos sociais aos quais pertenciam as crianças apresentavam condições sociais muito distintas que lhes afetavam a capacidade de responder a uma oferta e aproveitar bem as oportunidades oferecidas, o que fazia com que a igualdade na oferta fosse insuficiente para garantir a equidade da política.

A partir dai, o conceito de equidade educacional foi-se complexificando para se tornar cada vez mais um conceito multidimensional (MOKATE, 2001), incorporando geralmente, além da cobertura, a avaliação do acesso -objeto deste artigo -, insumos, processos ou fluxos, e efeitos ou resultados ${ }^{2}$. No caso do acesso à educação, a avaliação da equidade leva em conta, mais que a oferta, principalmente a capacidade desigual entre a população para fazer uso dos recursos e serviços educacionais disponibilizados. Uma política para a garantia da equidade no acesso à educação deveria orientar-se para a igualdade das condições efetivas para que todos os grupos sociais possam ter acesso efetivo à educação, ainda que isso signifique em alguns casos uma distribuição desigual de benefícios em favor dos grupos mais vulneráveis. Esse tipo de política incluiria programas como bolsa- família ou bolsa-escola, o encurtamento dos custos de deslocamento das crianças (garantindo a existência de escolas próximas à sua clientela ou, no mínimo, transporte escolar), qualificar a demanda, fornecendo informação e convencendo as famílias mais vulneráveis, etc. Nos termos de Mokate (2001, tradução nossa), equidade no acesso à educação implica: "Fazer com que o esforço relativo que os usuários tenham que fazer para aproveitar o serviço ou o programa seja aproximadamente igual".

De fato, a explicação da desigualdade de oportunidades educacionais deve levar em conta tanto o perfil, a magnitude e a distribuição da oferta quanto da demanda, ou seja, um conjunto de características familiares das crianças que favorece ou não sua educação ${ }^{3}$. A literatura aponta pelo menos três ordens relevantes de recursos dos quais as famílias podem dispor e que impactam as chances educacionais das

2 A dimensão de insumos, cujo foco é a oferta educacional, inclui a alocação a diferentes grupos, de recursos financeiros, qualificação docente, equipamentos, entre outros. A dimensão dos processos ou fluxos é geralmente observada por meio da análise de como o sistema educacional se comporta em relação aos diferentes grupos quanto a variáveis como abandono, reprovação, atraso escolar, taxa de conclusão. Finalmente, os resultados, do ponto de vista da equidade interna, são medidos por meio do desempenho de diferentes segmentos em testes padronizados de aprendizagem, mostrando geralmente que a eficácia do sistema educacional não é aleatoriamente distribuída em relação aos diferentes grupos.

3 Um marco importante no debate - acadêmico e político - acerca da desigualdade de oportunidades educacionais foi o chamado Relatório Coleman, publicado em 1966. A expectativa em torno do Relatório era que ele apontasse diferenças importantes, em termos de insumos e infra-estrutura, principalmente entre escolas que atendiam majoritariamente crianças brancas e as de maioria negra, e que se pudesse atribuir a elas a desigualdade em termos de desempenho escolar entre alunos brancos e negros, o que legitimaria intervenção federal massiva nas escolas de guetos. Os resultados do estudo apontaram, porém, para outra direção. Não se encontraram diferenças relevantes entre as escolas com clientelas majoritariamente brancas e com clientelas majoritariamente negras e, além disso, as diferenças entre os insumos e recursos das escolas não tinham impacto significativo sobre o desempenho dos alunos. Diante disso, Coleman (1966) afirma que as características familiares seriam muito mais importantes do que as características das escolas para explicar as diferenças de desempenho dos alunos.

Ensaio: aval. pol. públ. Educ., Rio de Janeiro, v. 18, n. 68, p. 465-488, jul./set. 2010 
crianças. Em primeiro lugar, o capital econômico, normalmente medido pela renda familiar e que indica as possibilidades de as famílias proporcionarem certas condições (inclusive físicas) para seus filhos em idade escolar (local adequado de estudo, acesso a material didático, etc.). Em segundo lugar, analisam o capital cultural, normalmente medido pela escolaridade dos pais ou da mãe, e, às vezes, pelo consumo cultural da família, que indica o clima e os recursos educacionais disponiveis para as famílias auxiliarem e acompanharem a vida escolar de suas crianças, bem como para avaliar a qualidade da educação oferecida pela escola, dentre outras habilidades. Finalmente, o terceiro tipo de recurso é o capital social, abordado pioneiramente por Coleman, e que se refere, no que concerne à educação, à natureza das relações entre pais e filhos, notadamente à atenção que os adultos podem dar às crianças, sendo mais deficitário (de um ponto de vista quase aritmético) nas famílias monoparentais e nas famílias com muitos filhos ${ }^{4}$ (VALLE; HASENBALG, 2000; WILLMS; SOMERS, 2000).

Evidentemente, tais fatores são fortemente atravessados pelas condições socioeconômicas e pela desigualdade social, em desvantagem para as famílias mais pobres, o que tende a limitar as possibilidades da escolarização como mecanismo corretor de desigualdades. Avaliar, portanto, a condição de equidade no ensino fundamental implica uma análise multidimensional que leve em conta as diferentes condições, em termos de situação socioeconômica das famílias e de intervenção pública que restringem ou ampliam as oportunidades educacionais de crianças e adolescentes.

\section{Hipóteses sobre determinantes de acesso à educação entre crianças/ adolescentes em situação de rua}

A partir da discussão acima, é possivel elaborar, para o grupo específico a ser analisado - crianças e adolescentes em situação de rua (vida ou trabalho) em municípios mineiros - um conjunto de hipóteses analíticas e empíricas que permitem explorar a validade de alguns dos determinantes do acesso à educação apontados na literatura, quando se lida com contextos de particular vulnerabilidade. Note que a variável dependente a ser considerada é o acesso à educação, medido da maneira mais simples: avalia se o entrevistado frequenta ou não a escola. De maneira geral, pode-se esperar que, dadas as condições socioeconômicas deste grupo, de maneira geral, a taxa de frequência à escola dos entrevistados será inferior à taxa de escolarização global da população nesta faixa etária.

4 Os estudos mais recentes apontam também a intensidade, a regularidade e as características da relação da família (principalmente pais) com a escola como um fator importante para o desempenho das crianças 
Quanto às possíveis variáveis independentes, uma primeira hipótese considera uma situação limite. Pode-se esperar que a probabilidade de uma criança frequentar a escola reduz-se muito fortemente quando ela vive nas ruas a maior parte do tempo. As razões são óbvias: a ausência das condições mínimas de estudo, local de referência, material escolar, supervisão dos adultos, precariedade das fontes de provisão material, entre outros fatores restringirão fortemente ou eliminarão as chances destas crianças terem acesso à escola.

Uma segunda variável tem a ver com a idade. Como ocorre com a população em geral, a tendência será a de que a probabilidade de frequentar a escola se reduza com a idade. Isto tem a ver justamente com a discussão acima, que ressalta que grupos diferentes tendem a ter recursos diferentes para acessar e utilizar produtivamente as oportunidades educacionais. Quando se considera a educação como um investimento que as familias fazem no futuro de seus filhos, há que se prestar atenção não apenas na avaliação dos benefícios, mas também na desigualdade dos custos e no seu peso sobre as famílias. Manter um membro da família estudando sem trabalhar é um investimento: a família investe na educação como se fizesse um cálculo do acréscimo futuro de rendimentos e oportunidades que a educação poderia proporcionar às crianças e aos adolescentes, menos seus custos, inclusive a menor renda atual do trabalho. A partir de determinada idade e escolaridade, tanto os ganhos adicionais de renda que o adolescente poderia ter com o aumento da escolaridade quanto às suas oportunidades educacaionais futuras passam a não compensar a renda imediata a mais que seu ingresso no mercado de trabalho proporciona - ou essa, ao menos, é a percepção - e a pressão para o trabalho aumenta à custa do acesso, investimento e manutenção das crianças na escola ${ }^{5}$.

Quanto a esta relação, a literatura tem apontado que o ingresso precoce no mercado de trabalho e as condições em que se dá este ingresso tendem a limitar o acesso e permanência de adolescentes na escola. Quanto a isto, as evidências examinadas permitem uma avaliação parcial do problema. A grande maioria do público entrevistado desenvolve, em sentido amplo ${ }^{6}$, algum tipo de trabalho. Entretanto, pode-se avaliar se as condições de trabalho influenciam as oportunidades educacionais das crianças e adolescentes em situação de rua. Assim, espera-se que maiores jornadas de trabalho (avaliadas, por exemplo, em termos do número de dias que os entrevistados vêm para as ruas) estejam associadas a uma menor probabilidade de frequentar a escola.

5 Este é mais um dos motivos pelos qual a cultura da repetência é prejudicial particularmente para os grupos mais vulneráveis: cada ano repetido aumenta muito o custo de oportunidade de educação para os mais pobres e reduz as expectativas sobre as oportunidades e o alcance educacional das crianças, contribuindo duplamente para o ingresso no mercado de trabalho e abandono da escola.

6 A definição operacional do que pode ser considerado trabalho ou ocupação é sabidamente controversa. Do ponto de vista deste trabalho e considerando a especificidade do público, considerou-se a definição mais abrangente de trabalho: qualquer atividade realizada com vistas a obter algum tipo de remuneração em dinheiro. Isto incluiu desde atividades mais tradicionais, como ambulante ou panfletista, até atividades flagrantemente ilícitas, como prostituição ou tráfico. 
Deslocando a análise mais específica do capital econômico das famílias e de suas consequências sobre as oportunidades educacionais, os dados permitem explorar também os efeitos do capital social sobre a frequência escolar, conforme a discussão acima. Neste caso, espera-se que a probabilidade de frequentar a escola seja reduzida à medida em que o número de irmãos aumenta; dito de outra maneira, quanto maior o número de irmãos, menor a probabilidade de uma criança ou adolescente frequentar a escola.

De outro lado, a literatura aponta que um evento que impacta fortemente o capital social das crianças e adolescentes e de suas familias (além de efeitos mais diretos sobre as condições materiais) é a ocorrência de gravidez precoce. Esperase, assim, que a probabilidade de frequentar a escola seja significativamente menor entre os adolescentes que declararam ter filhos.

Dados os efeitos limitadores das condições socioeconômicas e familiares das crianças e adolescentes sobre suas oportunidades educacionais e sobre o papel igualador da educação, cabe explorar em que medida as principais intervenções públicas ampliam o acesso de grupos vulneráveis à escola. 0 trabalho avalia dois tipos de intervenção: de um lado os programas que envolvem transferência condicionada de renda, notadamente o Programa Bolsa-Família e o Programa de Erradicação do Trabalho Infantil. No primeiro caso, o recebimento do benefício altera os custos de oportunidade da frequência à escola e ajuda a família a lidar com os outros custos da educação, o que juntamente à exigência de frequência escolar, ampliaria a chance de que as crianças frequentem a escola. No caso do PETI, além da renda recebida pela família, a exigência de frequência às chamadas atividades complementares, criaria espaços de convivência supervisionados e nos quais os valores, atividades e relações apoiariam a frequência escolar, ampliando o capital social e cultural das crianças. Espera-se, portanto que, sendo constantes os demais fatores, as crianças e adolescentes beneficiários destes programas apresentem maior probabilidade de frequentar a escola.

Finalmente, a pesquisa avaliou ainda a participação em outros projetos sociais que não envolvam a transferência direta de renda. São projetos diversos, públicos e não governamentais, que geralmente envolvem atividades complementares à escola, esporte, lazer, o chamado reforço escolar, entre outras. Como são intervenções que, em geral, criam condições sociais e culturais mais favoráveis à escolarização, mas não produzem efeitos diretos sobre as condições socioeconômicas das famílias, o que se espera é que tenham também algum um efeito positivo sobre a probabilidade de acesso à escola.

Estas hipóteses orientarão em seguida a análise dos dados das crianças e adolescentes em situação de rua em 21 municipios mineiros. 


\section{Análise empírica}

Este trabalho se baseia nos resultados de uma pesquisa realizada simultaneamente em 21 municípios do estado de Minas Gerais, ao final de 2007, e que teve como objeto de análise todas as crianças e adolescentes com idade até 18 anos incompletos que estivessem morando ou exercendo qualquer tipo de ocupação nas ruas (por exemplo, comércio, pedintes, prostituição). Todavia, quando da análise empírica dos determinantes da escolarização, apenas as crianças com mais de seis anos de idade foram consideradas, excluindo-se as demais.

Nesse trabalho foi definido como criança e adolescente em situação de rua aquelas que se enquadram na conceituação de Rizzini (2003, p. 13-14): "Crianças e adolescentes que se movimentam entre suas casas, as ruas e as instituições, em busca de proteção e de um lugar onde se sintam pertencentes, sendo diversos os fatores que determinam os processos excludentes que afetam a vida de cada uma destas crianças e suas famílias".

Operacionalmente, e em função da natureza da pesquisa, estabeleceu-se que todas as crianças e adolescentes encontrados nas ruas e logradouros públicos morando nesses locais ou exercendo quaisquer tipos de ocupação em quaisquer horários seriam considerados como público da pesquisa e, por isso, seriam entrevistados. Também foram incluídas aquelas crianças e adolescentes que estivessem em instituições do tipo "casas de passagem" e "abrigos" a menos de três meses em relação à data da pesquisa.

Em todo esse processo foram mobilizados e interligados para o trabalho mais de 460 pessoas nos municípios pesquisados, entre parceiros e entrevistadores. Especificamente na obtenção dos dados foram assumidos os riscos comumente envolvidos em pesquisas do tipo survey? ${ }^{7}$. Com relação aos entrevistadores de campo, estes foram, basicamente, funcionários e/ou representantes de entidades de âmbito municipal que possuiam profundos conhecimentos do público analisado.

No total, foram abordadas 3.028 crianças e adolescentes nos 21 municípios no período de 20 a 26 de agosto de 2007 (semana de referência da pesquisa) ${ }^{8}$. Após serem abordadas, as crianças e adolescentes respondiam a um questionário com 25 questões, onde as perguntas foram organizadas em sete blocos: características individuais, educação, família, ocupação nas ruas, características do local onde moravam, saúde/ violência e expectativa de vida?

7 Como, por exemplo, problemas na identificação e na abordagem do público alvo, má compreensão dos quesitos do questionário, e fornecimento de informações falsas por parte do entrevistado.

8 Nessa pesquisa, os questionários válidos representaram 83,19\% (2.519 formulários) do universo pesquisado e as recusas representaram 16,81\% (509 formulários).

90 questionário utilizado está disponível em caso de solicitação aos autores. 
De uma maneira geral, avaliou-se que a qualidade dos dados obtidos nos municípios foi bastante adequada no que se refere aos aspectos de confiabilidade e validade. No limite, apenas os dados do município de Uberlândia alcançaram um grau de confiabilidade inferior ao da média da pesquisa; ainda assim, optou-se por incluí-los nas análises que se seguem ${ }^{10}$.

Os municipios escolhidos foram: Almenara, Belo Horizonte, Betim, Contagem, Divinópolis, Governador Valadares, Ibirité, Ipatinga, Janaúba, Juiz de Fora, Montes Claros, Muriaé, Ouro Preto, Poços de Caldas, Ribeirão das Neves, Sabará, Santa Luzia, Teófilo Otoni, Uberaba e Uberlândia. Esses municípios, em conjunto, representam aproximadamente 35\% da população do estado, sendo que sete deles são integrantes da Região Metropolitana de Belo Horizonte (Belo Horizonte, Contagem, Betim, Ribeirão das Neves, Sabará, Santa Luzia e Ibirité).

A tabela 1 expressa o porcentual de crianças e adolescentes entrevistadas por sexo. Observa-se a porcentagem mais baixa da presença das mulheres, se comparada à dos homens, em todos os municípios estudados. A cidade de Janaúba apresenta a maior "distorção" entre meninos e meninas: 96,77\% para homens, e 3,23\% para mulheres. Por outro lado, o municipio de Betim apresenta os porcentuais mais baixos, com $61,67 \%$ para homens e $38,33 \%$ para mulheres.

10 Nesse caso, os responsáveis pela pesquisa nesse município tiveram problemas de ordem institucional na mobilização de recursos para o desenvolvimento dos trabalhos. 
Tabela 1: Porcentual de Sexo dos questionários válidos, por municípios.

\begin{tabular}{c|c|c|c}
\hline Municipios & \multicolumn{3}{|c}{ Sexo (\%) } \\
\hline Almenara & Homens & Mulheres & Total \\
\hline Belo Horizonte & 90,99 & 9,01 & 100,00 \\
\hline Betim & 76,25 & 23,75 & 100,00 \\
\hline Contagem & 61,67 & 38,33 & 100,00 \\
\hline Divinópolis & 77,30 & 22,70 & 100,00 \\
\hline Gov. Valadares & 86,33 & 13,67 & 100,00 \\
\hline Ibirité & 93,86 & 6,14 & 100,00 \\
\hline Ipatinga & 82,39 & 17,61 & 100,00 \\
\hline Janaúba & 79,35 & 20,65 & 100,00 \\
\hline Januária & 96,77 & 3,23 & 100,00 \\
\hline Juiz de Fora & 86,84 & 13,16 & 100,00 \\
\hline Montes Claros & 82,05 & 17,95 & 100,00 \\
\hline Muriaé & 95,12 & 4,88 & 100,00 \\
\hline Ouro Preto & 76,52 & 23,48 & 100,00 \\
\hline Poços de Caldas & 90,91 & 9,09 & 100,00 \\
\hline Ribeirão das Neves & 90,91 & 9,09 & 100,00 \\
\hline Sabará & 92,86 & 7,14 & 100,00 \\
\hline Santa Luzia & 78,79 & 21,21 & 100,00 \\
\hline Teófilo Otoni & 88,24 & 11,76 & 100,00 \\
\hline Uberaba & 90,53 & 9,47 & 100,00 \\
\hline \hline
\end{tabular}

Fonte: Ferreira, Costa e Rais (2007).

A Tabela. 2 indica a distribuição das crianças entrevistadas por grupos de idade. A cidade de Sabará possui maior percentual relativo de crianças $(9,26 \%)$, enquanto a cidade de Divinópolis indica ter o maior percentual relativo de adolescentes $(57,46 \%)$. Deve-se observar que do total de crianças e adolescentes nas ruas o grupo de idade entre 7 e 14 anos representa mais de $57 \%$ do total das crianças encontradas. 
Tabela 2: Faixas etárias, população de rua de crianças e adolescentes por municipios.

\begin{tabular}{|c|c|c|c|}
\hline \multirow[t]{2}{*}{ Municípios } & \multicolumn{3}{|c|}{ Idades (\%) } \\
\hline & 0 a 6 anos & 7 a 14 anos & 15 a menos 18 anos \\
\hline Almenara & 1,09 & 75,00 & 23,91 \\
\hline Belo Horizonte & 8,03 & 48,32 & 43,65 \\
\hline Betim & 5,45 & 40,00 & 54,55 \\
\hline Contagem & 7,58 & 53,03 & 39,39 \\
\hline Divinópolis & 0,75 & 41,79 & 57,46 \\
\hline Gov. Valadares & 1,85 & 69,44 & 28,70 \\
\hline Ibirité & 4,70 & 64,43 & 30,87 \\
\hline Ipatinga & 1,72 & 65,67 & 32,62 \\
\hline Janaúba & 3,70 & 55,56 & 40,74 \\
\hline Januária & 0,00 & 87,10 & 12,90 \\
\hline Juiz de Fora & 5,41 & 40,54 & 54,05 \\
\hline Montes Claros & 0,67 & 74,67 & 24,67 \\
\hline Muriaé & 2,83 & 60,38 & 36,79 \\
\hline Ouro Preto & 0,00 & 50,00 & 50,00 \\
\hline Poços de Caldas & 0,00 & 55,56 & 44,44 \\
\hline Ribeirão das Neves & 1,49 & 43,28 & 55,22 \\
\hline Sabará & 9,26 & 50,00 & 40,74 \\
\hline Santa Luzia & 3,70 & 59,26 & 37,04 \\
\hline Teófilo Otoni & 2,63 & 75,00 & 22,37 \\
\hline Uberaba & 4,14 & 72,41 & 23,45 \\
\hline Uberlândia & 5,26 & 63,16 & 31,58 \\
\hline
\end{tabular}

Fonte: Ferreira, Costa e Rais (2007).

Especificamente com relação à educação foi perguntado às crianças e adolescentes no momento da entrevista se elas estavam estudando ou não. A Tabela 3 indica as respostas válidas obtidas por idade. É interessante observar que, conforme esperado, entre os 4 e 10 anos de idade, os porcentuais de crianças e adolescentes que estudam é em geral crescente, havendo uma reversão dessas taxas a partir dos 12 anos de idade, quando boa parte desses meninos e meninas entram na adolescência. Mais uma vez vale lembrar que foram desconsideradas as respostas dos menores de 6 anos quando da análise dos determinantes da escolarização. 
Tabela 3: Você Estuda? (População infantil de rua).

\begin{tabular}{c|c|c}
\hline Idade & Sim (\%) & Não (\%) \\
\hline 0 & 0,00 & 100,00 \\
\hline 1 & 0,00 & 100,00 \\
\hline 2 & 0,00 & 100,00 \\
\hline 3 & 8,30 & 91,70 \\
\hline 4 & 11,80 & 88,20 \\
\hline 5 & 23,10 & 76,90 \\
\hline 6 & 66,70 & 33,30 \\
\hline 7 & 86,40 & 13,60 \\
\hline 8 & 84,50 & 15,50 \\
\hline 9 & 94,20 & 5,80 \\
\hline 10 & 89,70 & 10,30 \\
\hline 11 & 90,10 & 9,90 \\
\hline 12 & 89,70 & 10,30 \\
\hline 13 & 85,90 & 14,10 \\
\hline 14 & 84,40 & 15,60 \\
\hline 15 & 76,40 & 23,60 \\
\hline 16 & 68,30 & 31,70 \\
\hline 17 & 62,73 & 37,27 \\
\hline
\end{tabular}

Fonte: Ferreira, Costa e Rais (2007).

Com base nos dados colhidos pela pesquisa, procurou-se aventar alguns determinantes das probabilidades de as crianças e adolescentes em situação de rua estarem estudando ou não. Para isso, foi estimado um modelo Logit, o qual possibilita a determinação de uma relação funcional entre a probabilidade de ocorrência " $P$ " da variável dependente, considerando mudanças no comportamento ou distribuição nas variáveis independentes (ou explicativas). Uma análise um pouco mais detaIhada do modelo estimado é apresentada no apêndice.

\section{Resultados da estimação}

Os resultados do modelo estimado são apresentados na Tabela abaixo. Testes de diagnóstico confirmam a robustez do mesmo; em especial, a razão de verossimiIhança (LR) indica significância conjunta das variáveis incluídas na estimação, e o (pseudo) R-quadrado de 0.242 é sumamente razoável para modelos Logit ${ }^{11}$. Uma dificuldade de modelos como o estimado é que os coeficientes encontrados não representam efeitos marginais, o que complica ligeiramente a interpretação dos

11 Após a exclusão dos questionários das crianças com menos de seis anos de idade, bem como daqueles que continham uma ou mais respostas incompletas, o número de observações efetivamente utilizado na estimação foi reduzido para 1.633, o que ainda nos oferece razoáveis graus de confiança. 
resultados, que deve ater-se à discussão do sinal e da significância das variáveis. Para facilitar a compreensão dos resultados, computamos também as probabilidades de estudo para algumas variáveis específicas.

Tabela 4: Determinantes da escolarização de crianças/adolescentes em situação de rua.

\begin{tabular}{l|c|c|c}
\hline Variável & Coeficiente & Desvio - Padrão & Prob. \\
\hline Dias de trabalho semanais & -0.166 & 0.034 & 0.000 \\
\hline Dormiu em alguma instituição & -1.475 & 0.192 & 0.000 \\
\hline Idade & -0.180 & 0.031 & 0.000 \\
\hline Mora na rua & -2.393 & 0.407 & 0.000 \\
\hline Número de irmãos & -0.051 & 0.026 & 0.047 \\
\hline Possui Filhos & -0.774 & 0.356 & 0.030 \\
\hline Problema de saúde & -0.262 & 0.191 & 0.170 \\
\hline Programa social & 0.435 & 0.166 & 0.009 \\
\hline Região metropolitana & -0.442 & 0.148 & 0.003 \\
\hline Sexo & -0.142 & 0.198 & 0.473 \\
\hline Transferência condicionada & 0.667 & 0.154 & 0.000 \\
\hline Vitima de violência & -0.694 & 0.187 & 0.000 \\
\hline Constante & 5.333 & 0.514 & 0.000 \\
\hline Média da var. dependente & 0.793145 & Estatística LR (12 df) & 410.2271 \\
\hline Desvio-padrão var. dep. & 0.405173 & Prob. (LR estat.) & 0.000000 \\
\hline Desvio - Padrão da regressão & 0.347446 & McFadden R-quadrado & 0.241956 \\
\hline Soma resíduos quadrados & 199.1863 & Critério Akaike & 0.788475 \\
\hline
\end{tabular}

Fonte: Ferreira, Costa e Rais (2007).

Em primeiro lugar, cabe uma nota sobre a ausência da variável "renda familiar" no modelo estimado. Hipóteses bastante plausíveis podem ser levantadas sobre a correlação entre essa variável e a escolarização das crianças/adolescentes de rua. Todavia, os dados conseguidos pela pesquisa sobre essa variável são muito pouco confiáveis, além de serem, de maneira geral, incompletos ${ }^{12}$. Por outro lado, por se tratar de uma população integralmente composta de crianças/adolescentes de rua, não se espera uma grande variação na renda familiar. Assim, pesando-se vantagens e desvantagens, optou-se por excluir do modelo a variável "renda familiar".

Com relação aos resultados encontrados, estes vão na direção de nossas hipóteses anteriores à estimação do modelo. As variáveis que possuem sinais negativos, ou seja, que estão negativamente correlacionadas com a variável "estuda", são: "dias de

12 A maior parte das crianças/adolescentes entrevistadas alegou não saber a renda familiar, o que implicou em um grande número de questionários sem essa resposta. Além disso, dentre os questionários que incluem esse dado, grande parte deles apresenta respostas pouco confiáveis. 
trabalho semanais", "dormiu em alguma instituição", "idade", "mora na rua", "número de irmãos", "possui filhos", "problema de saúde", "sexo", e "vítima de violência". Por outro lado, as variáveis positivamente correlacionadas com a variável "estuda" são: "programa social" e "transferência condicionada". As únicas variáveis que não são estatisticamente significantes são "sexo" e "problema de saúde"13, de maneira que sugere-se bastante parcimônia ao discutir os impactos dessas variáveis sobre a escolarização. Todas as demais variáveis são significantes pelo menos ao nível de $5 \%$, sendo a maioria significante ao nível de $1 \%$.

É interessante notar o efeito negativo do controle por "região metropolitana" sobre os resultados. Esse resultado lança um ponto para ampla discussão no que diz respeito à necessidade da implantação de políticas públicas focadas nos moradores de regiões metropolitanas, que se daria em sobreposição às políticas voltadas para 0 restante do estado. Nesse sentido, a experiência da Prefeitura de Belo Horizonte, bem como de outras capitais, com uma complementação municipal do Programa Bolsa-Família, parece importante, à luz dos resultados encontrados.

Como esperado, a variável "dias de trabalho semanais" aparece com sinal negativo. Conforme discutido anteriormente, intuitivamente é fácil perceber que o aumento do número de dias de trabalho semanais deve estar associado com um decréscimo na "chance" de que uma criança ou adolescente esteja na escola. Efeito semelhante é encontrado para a variável "idade".

Uma análise mais clara do impacto dessas duas variáveis pode ser vista nos gráficos abaixo, que mostram a variação das probabilidades de estudo de uma criança em situação de rua dada mudanças marginais na idade e no número de dias trabalhados ${ }^{14}$. Como discutido anteriormente, o forte impacto negativo do controle "região metropolitana" pode ser percebido nos gráficos. Todavia, mesmo no caso de crianças moradoras do interior percebe-se a importância das variáveis para explicar quedas nas probabilidades de estudo. Ambos os efeitos reforçam a relevância de políticas públicas voltadas tanto à erradicação do trabalho infantil, quanto à manutenção de adolescentes nas escolas.

13 Modelos que excluem essas variáveis foram testados, não afetando os resultados apresentados no artigo. Optou-se por manter as variáveis no modelo como forma de condicionar nossos resultados a essas variáveis que, embora não significantes, nos parecem bastante intuitivas.

14 No Gráfico 1, tomamos como base variações marginais nos dias trabalhados para uma criança do sexo masculino com 10 anos de idade e 3 irmãos (supondo valores nulos para todas as demais variáveis). No Gráfico 2 tomamos como base variações marginais na idade para uma criança do sexo masculino que trabalhe 3 dias por semana e tenha 3 irmãos (novamente supondo valores nulos para todas as demais variáveis). 


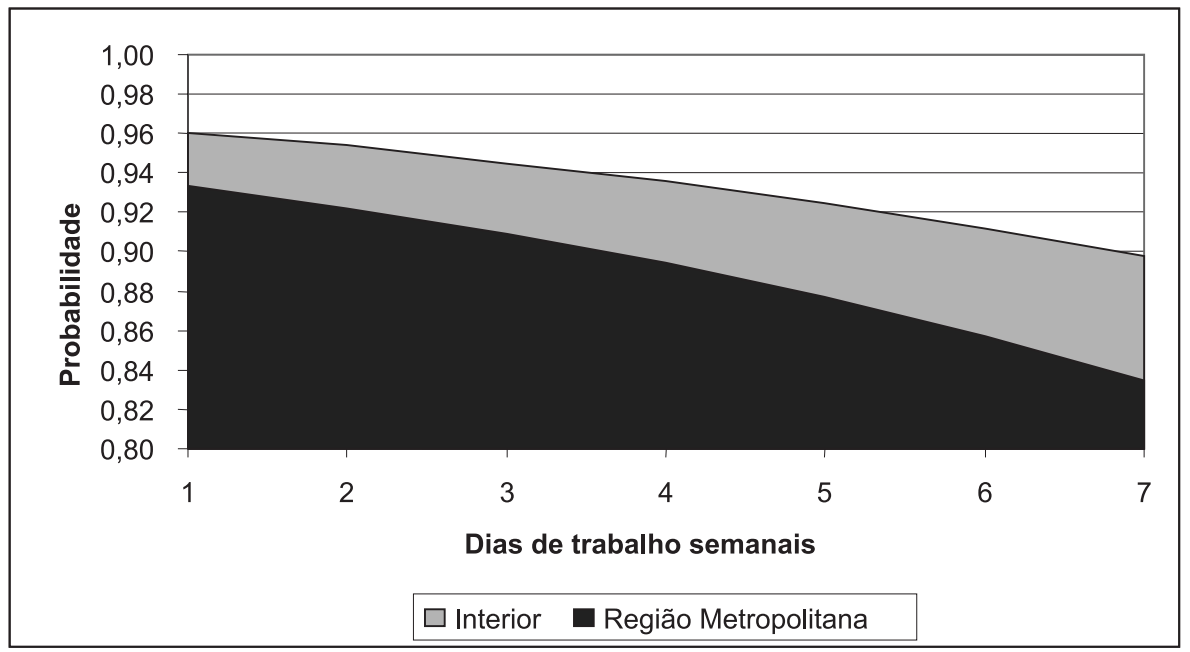

Gráfico 1: Probabilidade de estudo para variações marginais nos dias de trabalho. Fonte: Os autores (2007).

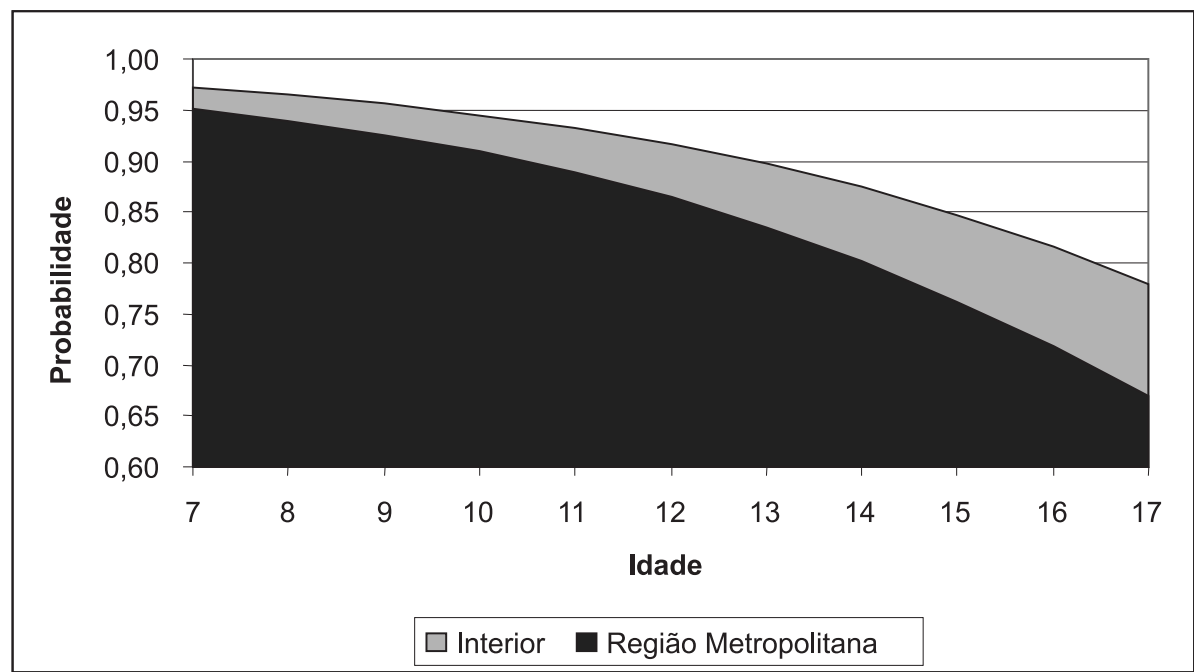

Gráfico 2: Probabilidade de estudo para variações marginais na idade. Fonte: Os autores (2007). 
A variável "dormiu em alguma instituição" também possui efeito fortemente negativo e significante sobre a variável "estuda". Igualmente negativo é o efeito da variável "mora na rua" sobre a "chance" de estudo. Ambos os resultados reforçam nossas hipóteses anteriores à estimação do modelo, e mostram a importância da questão da fragilidade habitacional sobre o acesso à educação. Isso é mais facilmente notado nos gráficos abaixo, os quais apresentam variações na probabilidade de estudo de uma hipotética criança do sexo masculino, com 10 anos, três irmãos e trabalhando três dias semanais, para diferentes respostas às variáveis "mora na rua" e "dormiu em instituição". Em ambos os casos as quedas nas probabilidades são extremamente relevantes em caso de respostas positivas às variáveis. Mais uma vez o controle "região metropolitana" reforça a pior situação educacional média para crianças que não sejam moradoras do interior do estado ${ }^{15}$.

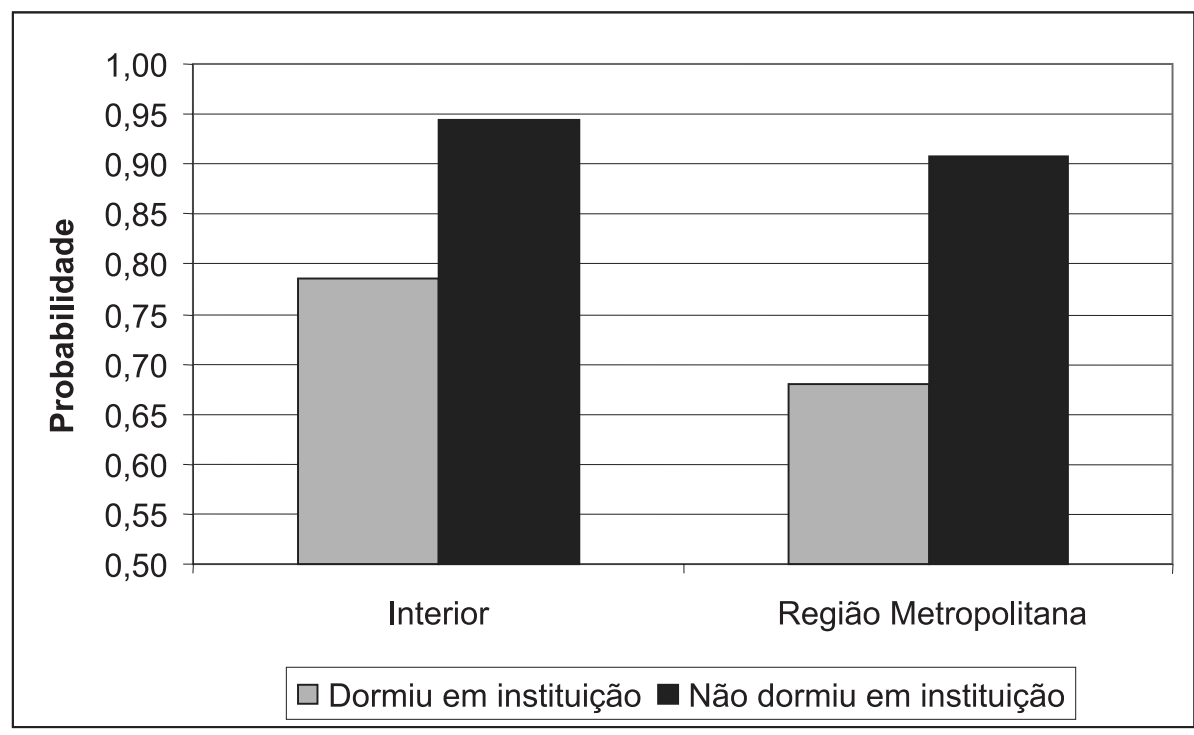

Gráfico 3: Probabilidade de estudo dada variável "dormiu em instituição". Fonte: Os autores (2007).

15 No entanto, neste caso, talvez o que estas evidências demonstrem, olhando de outro ângulo, seja a força e não a fragilidade da escolarização: na situação limite de destituição, vulnerabilidade e exposição a riscos que é uma criança ter a rua de uma metrópole como local de "moradia", ainda assim, há uma probabilidade de 0,5 de que esta criança frequente escola, o que é contra intuitivo e muito significativo da demanda por escolaridade na sociedade brasileira. 


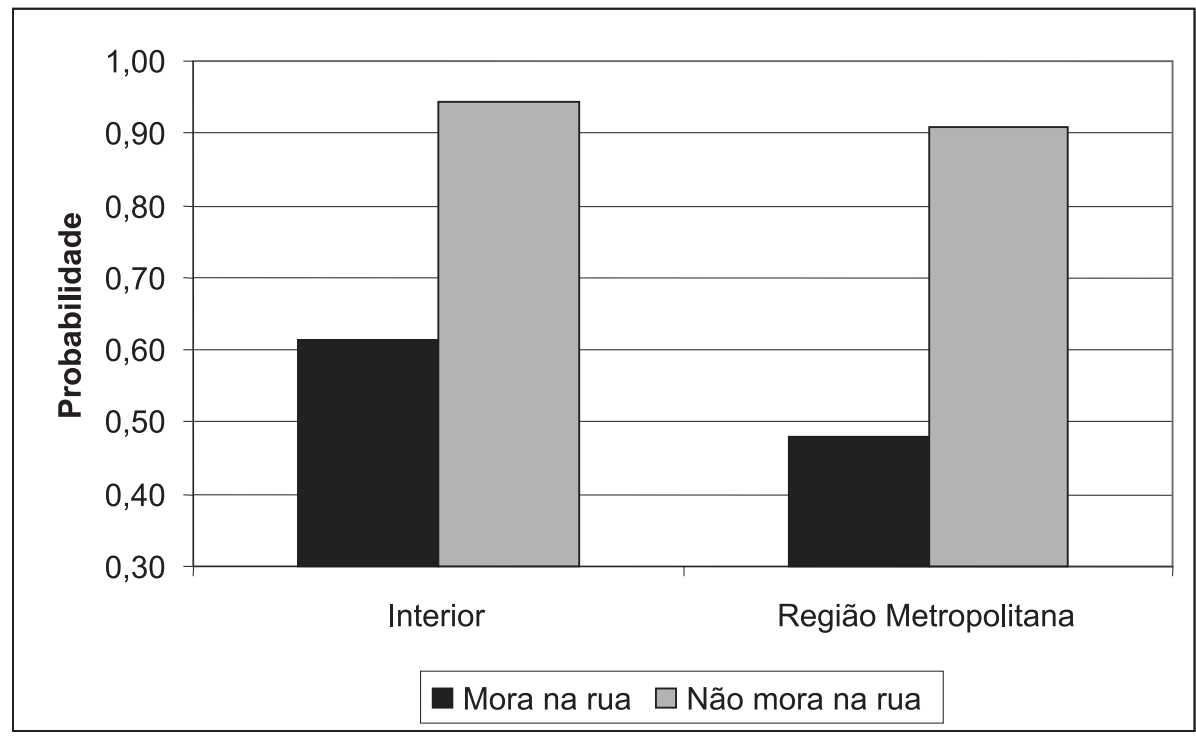

Gráfico 4: Probabilidade de estudo dada variável "mora na rua". Fonte: Os autores (2007).

Também conforme esperado, o "número de irmãos" também parece estar associado negativamente com a variável "estuda", o que corrobora com toda a literatura relacionada com o capital humano. Além disso, efeito extremamente forte e de implicações muito importantes se refere à variável "possui filhos". Como discutido anteriormente, diversos estudos têm mostrado que a paternidade na adolescência é um dos mais negativamente impactantes fenômenos na vida de um individuo. Nossos resultados reforçam esse argumento. Indubitavelmente esse resultado traz à tona a importância de que se discutam políticas mais amplas e eficazes no que diz respeito à redução da gravidez na adolescência. Esse resultado é mais bem apresentado no Gráfico 5, o qual mostra as diferentes probabilidades de estudo para um hipotético adolescente do sexo masculino, com 16 anos, que trabalhe cinco dias por semana e possua três irmãos, em virtude das respostas distintas à questão "possui filhos". As quedas de probabilidade de estudo são extremamente fortes, situadas ao redor de 20 pontos percentuais tanto no caso do interior quanto no da região metropolitana. 


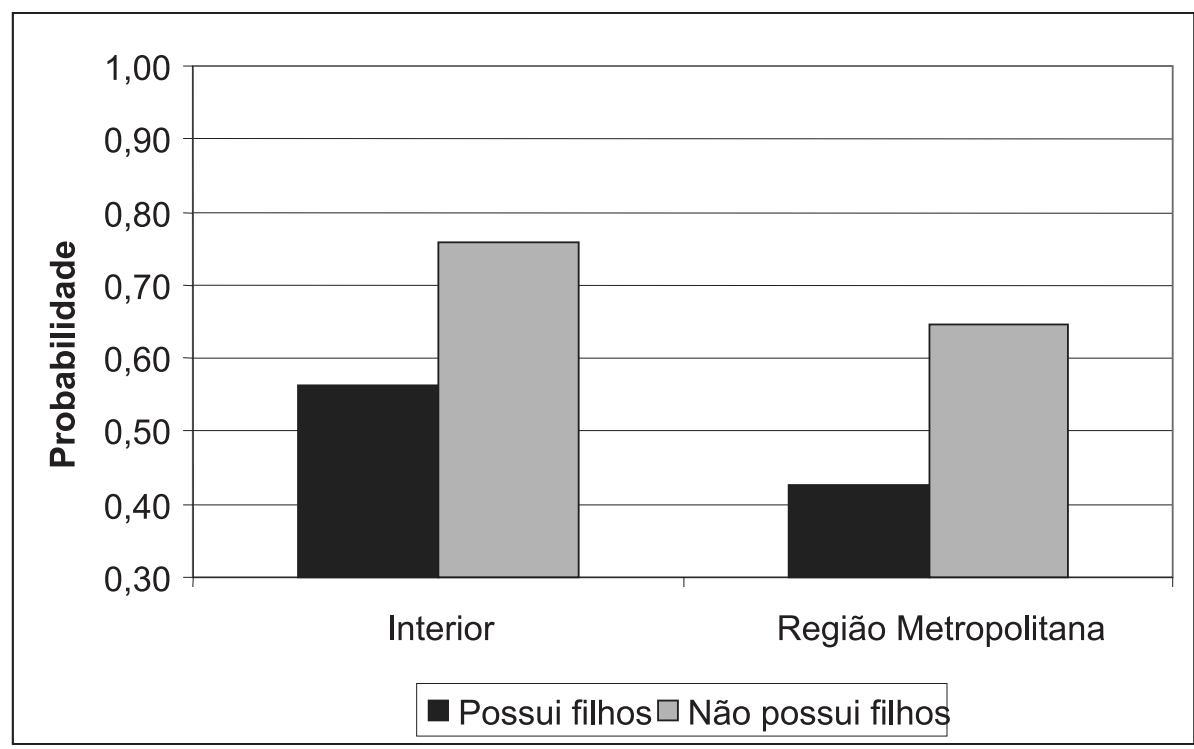

Gráfico 5: Probabilidade de estudo dada variável "possui filhos". Fonte: Os autores (2007).

Como mencionado anteriormente, as variáveis "sexo" e "problema de saúde" possuem coeficientes de sinal negativo, porém não são estatisticamente diferentes de zero, isto é, não possuem um impacto estatístico significante sobre a variável "estuda". Nesse caso, nos abstemos de fazer uma discussão mais aprofundada sobre elas ${ }^{16}$.

Efeito também negativo é percebido com relação à variável "vítima de violência", que, na verdade, se refere não apenas à violência como também ao fato de a criança ou adolescente ter sido vítima de algum acidente (por exemplo, atropelamento).

Finalmente, analisemos as variáveis que possuem correlação positiva com a variável "estuda": "programa social" e "transferência condicionada". Conforme já mencionado, é fato esperado que políticas sociais promovam um aumento na "chance" de que crianças e adolescentes estudem. Em especial, programas de transferência condicionada (Bolsa Família e PETI) foram desenhados para obter esse tipo de resposta. Assim, é reconfortante notar que os resultados encontrados mostram uma elevação da "chance" de estudo entre as crianças e adolescentes que recebem tais benefícios.

16 De fato a insignificância da variável "sexo" pode ser usada como evidência comprovadora de que não existe discriminação educacional no Brasil (ou, pelo menos, no estado de Minas Gerais) com relação ao sexo, o que é um fato razoavelmente aceito entre pesquisadores do tema. 


\section{Comentários finais}

Este trabalho teve claramente um caráter exploratório. A avaliação da pertinência dos principais fatores apontados na literatura para explicar as diferenças no acesso à escola de um segmento das crianças e adolescentes, que compartilham um tipo específico e intenso de vulnerabilidade - a rua como referência central de vida ou trabalho - permite qualificar o debate sobre o acesso à educação.

De maneira geral, os resultados apresentados no artigo mostram um cenário bastante claro no que diz respeito aos determinantes da escolarização de crianças e adolescentes em situação de rua no estado de Minas Gerais. Os coeficientes encontrados, de maneira geral, correspondem às hipóteses derivadas da literatura relevante, conforme discorrido na segunda seção. Em especial, percebe-se a influência negativa (isto é, associadas a menores taxas de escolarização) da extensão da jornada de trabaIho, da qualidade habitacional, da idade, da gravidez na adolescência e da localização em município da região metropolitana. Por outro lado, políticas públicas de transferência de renda, particularmente as condicionadas, ampliam as possibilidades de estudo para as crianças e adolescentes expostas à vida ou ao trabalho nas ruas. Uma conclusão óbvia disso é que tais políticas devem ser não apenas incentivadas, mas complementadas por políticas que permitam e estimulem a manutenção dos adolescentes nas escolas, que apresentem alternativas à permanência nas ruas como espaço de vida ou trabalho, e que aprimorem a qualidade de vida nas regiões metropolitanas.

É interessante notar, por um lado, que as evidências demonstram que, apesar das muito fortes restrições materiais e familiares a que o grupo de crianças e adolescentes analisado neste trabalho está exposto, há sempre probabilidades altas de frequência à escola. Isto indica que há uma demanda e um esforço por parte das crianças e adolescentes e de suas famílias em garantir a escolaridade, contrariando a ideia de senso comum de que os grupos sociais mais vulneráveis valorizariam pouco a educação de seus filhos.

De outro lado, os dados demonstram que o acesso à educação é influenciado restringido ou ampliado - por um conjunto de fatores que não se limitam às dimensões mais diretamente econômicas: o capital social das famílias, maternidade ou paternidade precoce, jornada de trabalho, situação familiar e de moradia e, muito fortemente, idade.

Os dados demonstram ainda que há diferenças na magnitude e no perfil do fenômeno do uso das ruas que não parecem determinadas apenas pelos atributos individuais ou familiares. A proporção da população infanto-juvenil encontrada trabalhando ou vivendo nas ruas encontra bastante variação entre os municípios pesquisados, bem como o uso e as ocupações encontradas. As evidências indicam ainda que a influência destes fatores é potencializada em determinados contextos, particularmente nos municipios metropolitanos. Esta diversidade requer novos estudos que analisem os fatores mais 
territoriais, estruturais ou contextuais que permitam compreender as diferenças entre os municípios, o que permitiria avaliar, inclusive, a pertinência de intervenções mais adaptadas a contextos específicos, como os metropolitanos.

Mas a análise também indica que há o que fazer. As intervenções públicas ou não governamentais estão associadas com um aumento da probabilidade de escolarização. Bolsa Família, PETI e outros projetos têm aparentemente efeito significativo sobre a escolarização mesmo em um segmento particularmente vulnerável como as crianças e adolescentes em situação de rua. Ou seja, a ideia de que as ações que lidam com situações fortemente adversas seriam pouco efetivas ou estariam "enxugando gelo" parece subestimar o espaço possivel de intervenção sobre a escolarização.

\section{Referências}

CALERO, J.; BONAL, X. Política educativa y gasto público en educación. Barcelona: Pomares-Corredor, 1999.

COLEMAN, J. Equality of educational opportunity. Washington, D. C.: US Office of Education, 1966.

FERREIRA, F. P. M.; COSTA, B. L. D.; RAIS, N. Diagnóstico do trabalho infantil e situação de vida nas ruas de crianças e adolescentes em Minas Gerais, Belo Horizonte: relatório de pesquisa. Belo Horizonte, MG: Fundação João Pinheiro, 2007. Mimeografado.

MOKATE, K. Eficacia, eficiencia, equidade, sustentabilidad: que queremos decir?. Washington, DC: Indes/BID, 2001. (Series Documentos de Trabajo; I-24).

RIZZINI, I.; BUTLER, U. M. Crianças e adolescentes que vivem e trabalham nas ruas revisitando a literatura. In: RIZZINI, I. (Org.). Vida nas ruas, crianças e adolescentes nas ruas: trajetórias inevitáveis?. Rio de Janeiro: Ed. Puc-Rio, 2003.

SEN, A. Inequality reexamined. Cambridge: Harvard University Press. 1997.

VALLE, N.; HASENBALG, C. Tendências da desigualdade educacional no Brasil. Dados, Rio de Janeiro, v. 43, n. 3, p. 423-445, 2000.

VAN PARIJS, P. ¿Qué es una sociedad justa?. Barcelona: Ariel. 1993.

WILLMS, J. D.; SOMERS, M. Schooling outcomes in Latin America. Fredericton, Canada: University of New Brunswich, Canadian Research Institute for Social Policy, 2000.

Recebido em: 06/04/2009 
Aceito para publicação em: 17/06/2010

\section{APÊNDICE A: Regressão logística}

A Regressão Logística pode ser definida como um modelo linear generalizado com erro binomial e função de enlace logital (Hosmer e Lemeshow, 1989). Essa função permite estimar coeficientes $\beta$ (beta), os quais determinam uma relação funcional entre a probabilidade de ocorrência " $P$ " da variável dependente e cada uma das covariáveis " $x$ ". Na medida em que a relação entre $x$ e $P$ não é linear, b não tem a mesma interpretação nesse tipo de modelo como é feito nas regressões lineares ordinárias. No entanto, através de uma transformação logito é possível assumirmos a linearidade do modelo. Neste sentido, o logito, representa o logaritmo natural da "odds" e que pode ser dada por:

$$
L O G(\text { odds })=\log i t o(P)=L N\left(\frac{P}{1-P}\right)
$$

Assim, o logito é um logaritmo da odds e as odds são uma função da probabilidade " $P$ " da variável dependente. A partir dessas transformações, podemos escrever a função logística como:

$$
\log \text { ito }(P)=\alpha+\beta x_{i}
$$

Alguns pesquisadores preferem trabalhar mais com as probabilidades do que com as odds. Assim, a partir da equação logística, podemos transformá-la em termos de probabilidade, obtendo:

$$
P=\frac{e^{\alpha+\beta x_{i}}}{1+e^{\alpha+\beta x_{i}}}
$$

Os coeficientes neste tipo de modelo são de difícil interpretação. Do ponto de vista da estimação é interessante que a odds ratio $P_{j} / P_{k}$ não dependesse das outras categorias, especialmente se considerarmos o ponto de vista da análise de comportamento (GREENE, 1993). Assim, neste artigo optou-se por trabalhar com exercícios de simulação no cálculo das probabilidades, dadas certas sequências pré-definidas que privilegiassem as variáveis consideradas mais importantes. 